\title{
Characteristics of Patients with Post-Colonoscopy Unplanned Hospital Visit: A Retrospective Single-Center Observational Study
}

This article was published in the following Dove Press journal:

Clinical and Experimental Gastroenterology

\author{
Jasbir Makker ${ }^{1,2}$ \\ Danial Shaikh (iD) 1,2 \\ Harish Patel ${ }^{1,2}$ \\ Siddarth Hanumanthu ${ }^{1,2}$ \\ Haozhe Sun' \\ Bushra Zaidi ${ }^{1}$ \\ Madhavi Ravi ${ }^{1,2}$ \\ Bhavna Balar ${ }^{1,2}$ \\ 'Department of Medicine, BronxCare \\ Health System, Affiliated with Icahn School \\ of Medicine at Mount Sinai, Bronx, NY \\ 10457, USA; ${ }^{2}$ Division of Gastroenterology, \\ BronxCare Health System, Affiliated with \\ Icahn School of Medicine at Mount Sinai, \\ Bronx, NY 10457, USA
}

Background: Colonoscopy, although a low-risk procedure, is not without associated adverse events. The rates of major adverse events such as perforation and bleeding after a colonoscopy are well reported. The rates of minor incidents following a colonoscopy, however, are less well examined. Recently the Centers for Medicare and Medicaid Services (CMS) started public reporting on the quality of outpatient endoscopy facilities by using a measure of risk-standardized rates of unplanned hospital visits within 7 days of colonoscopy.

Aim: We intended to record and present the characteristics of our patient population who had an unplanned hospital visit within 7 days after undergoing colonoscopy in an outpatient setting.

Methods: This is a retrospective single-center observational study. During the study period of July 2018 to December 2019, we reviewed charts of all patients who returned to the emergency room within a week of undergoing an outpatient colonoscopy. Patient demographics, clinical data and details of colonoscopy were collected and analyzed.

Results: Of the 5344 outpatient colonoscopies performed, our post-colonoscopy emergency room visit rate was $1.05 \%(\mathrm{n}=56)$. The mean age of the participants was 58 years and $55 \%$ were male; $32 \%$ of our patients reported gastrointestinal symptoms such as abdominal pain or gastrointestinal bleeding. Patients with gastrointestinal symptoms had a higher rate of polypectomies performed $(36.4 \%$ vs $11.8 \%, \mathrm{P}=0.04)$ and reported higher illicit drug use $(31.9 \%$ vs $5.9 \%, \mathrm{P}=0.02)$ compared with those with non-gastrointestinal complaints. After colonoscopy, $41 \%$ of the patients reported reasons for emergency room visits that were entirely unrelated to the procedure.

Conclusion: Our study highlights that unplanned visits within 7 days of colonoscopy are not necessarily related to the procedure, and those that are, tend to be due to unavoidable patient factors. Hence the CMS measure may not be an accurate determinant of the quality of procedure or facility care delivered.

Keywords: colonoscopy, Centers for Medicare and Medicaid Services, CMS, 7-day readmission, adverse events, gastrointestinal symptoms, post-colonoscopy, unplanned visit

\section{Introduction}

The United States Preventive Services Task Force (USPSTF) recommends screening for colorectal cancer for all adults aged 50-75 years. Tools for screening for colorectal cancer are categorized into two groups, namely, direct visualization tests and stool-based tests. Colonoscopy is one of the most commonly used direct visualization tests in the United States and worldwide. Nearly 11 million
BronxCare Health System, Affiliated with Icahn School of Medicine at Mount Sinai

Bronx, 1650 Selwyn Ave, Bronx, NY

10457, USA

Tel + I 7/8-974-7383

$\mathrm{Fax}+1$ 718-960-2055

Email dshaikh@bronxcare.org
Clinical and Experimental Gastroenterology 2021:14 19-25 
colonoscopies were performed in the United States in 2013 alone. ${ }^{1}$ It is mostly performed for colorectal cancer screening and surveillance of colon polyps.

Colonoscopy, although considered a safe and low-risk procedure, may be associated with complications. The American Society for Gastrointestinal Endoscopy (ASGE) Quality Task Force has categorized colonoscopyrelated complications into two types; incidents and adverse events. $^{2}$ Adverse events are defined as

an event that prevents completion of the planned procedure and/or results in admission to hospital, prolongation of existing hospital stay, another procedure (needing sedation/anesthesia) or subsequent medical consultation. ${ }^{2}$

An incident was defined as a minor unwanted event that does not affect the plan of care, is self-limited, and has no sequelae. According to a recent meta-analysis, pooled prevalence rates of perforation and mortality after colonoscopies have remained stable and low at $0.05 \%$ and $0.0029 \%$, respectively. Moreover, the rates of bleeding after colonoscopy have declined over the last 15 years from $0.064 \%$ to $0.01 \%{ }^{3}$ Prevalence of minor incidents such as abdominal pain and distension after colonoscopy, though more common than major adverse events, are less well studied and reported. In a study conducted by Baudet et al., 31\% of their patients reported early (that occurred during stay in the endoscopy unit), and $23 \%$ of patients reported late (within 30 days) minor incidents after colonoscopy. ${ }^{4}$ In an effort to capture all unplanned visits after an outpatient colonoscopy, researchers recently studied claims data from Medicare beneficiaries and proposed an ambulatory colonoscopy care measure, named "Facility 7-Day Risk-Standardized Hospital Visit Rate after Outpatient Colonoscopy". 5

The primary aim of our study is to record and present the characteristics of our patients and their reasons for an unplanned visit to the emergency room within 7 days of colonoscopy.

\section{Patients and Methods}

This is a retrospective cohort review performed at a single center, between a study period of July 2018 to December 2019, looking at the characteristics of patients who had an unplanned visit to the hospital within 7 days after colonoscopy. The study protocol followed the ethical guidelines of the 1975 Declaration of Helsinki, as reflected in the Bronx Care Health System Institutional Review Board's (IRB) approval (Approval \# 03122003). Patient consent was not required by the IRB owing to the retrospective nature of the study and patient data confidentiality was maintained at each and every step of the study.

\section{Study Group}

We included all patients who had a colonoscopy performed as an outpatient at our facility during July 2018 to December 2019, irrespective of their age and insurance status. We reviewed charts of patients who had an unplanned visit to our emergency room within one week of their colonoscopy. We applied the same exclusion criteria used by the Centers for Medicare and Medicaid Services (CMS), and excluded the following patients:

- Colonoscopy done concurrently with a high risk upper gastrointestinal procedure done for control of bleeding from esophageal varices.

- Colonoscopy performed in patients with a history of inflammatory bowel disease.

- Colonoscopy performed in patients with a history of diverticulitis within the preceding one year.

- Colonoscopy performed in patients who were subsequently admitted electively.

\section{Clinical and Laboratory Parameters}

Clinical data such as age, gender, and ethnicity were collected from the electronic medical record. All comorbid medical conditions were noted. Details of the colonoscopy including indication of the procedure, total procedure time, insertion time, withdrawal time, procedure details, maneuvers such as abdominal pressure and patient repositioning performed to assist completion of the procedure, were also recorded. Post-colonoscopy emergency room visit records were reviewed. Reasons for the unplanned visits were reviewed. Imaging study and consultation reports if any requested for the patient were reviewed as well. Visits due to abdominal pain or gastrointestinal bleeding were deemed as "definitely" related to colonoscopy. Respiratory complaints such as shortness of breath; cardiovascular complaints such as chest pain, bradycardia and elevated blood pressure; neurological complaints such as headache, stroke and seizures; nephrology complaints such as oliguria were deemed as "probably" related to colonoscopy.

\section{Endpoints}

Primary aim was to record and present the data of our post-colonoscopy unplanned visits. Secondary aim was to 
explore any association between these unplanned visits and patient characteristics.

\section{Statistical Analysis}

Frequencies and percentages were reported for categorical variables. Mean and standard deviations were reported for numerical continuous variables. Dichotomous variables were compared by Chi-square analysis using the Pearson test. A two-tailed value of $\mathrm{P}<0.05$ was considered statistically significant.

\section{Results}

A total of 5344 outpatient colonoscopies were performed during the study period (July 2018 to December 2019). Sixty-eight unplanned visits to the emergency room occurred within 7 days after colonoscopy. Of these, 12 patient visits were excluded from the study based on the CMS exclusion criteria, as follows; one patient had concurrently performed high risk upper gastrointestinal endoscopy, five patients had history of inflammatory bowel disease, four patients had history of recent diverticulitis within the preceding one year, one patient had elective admission for surgery, and one patient had two visits after the procedure for the same reason.

A total of 56 unique patient visits were included in the study (Figure 1). Our overall post-colonoscopy unplanned emergency room visit rate was $1.05 \%$. The mean age of participants was 58 years, $55 \%$ were males and $45 \%$ were females; $48 \%$ of our patients were Hispanic, $46 \%$ were African Americans and the remaining 6\% belonged to other races.

Screening for colorectal cancer was the most common (41\%) indication for the procedure, followed by surveillance of colon polyps, and then diagnostic exams for evaluation of gastrointestinal bleed and iron deficiency anemia (Table 1). The mean insertion time, withdrawal time and total duration of colonoscopy among the study participants was $9 \pm 7$ minutes, $13 \pm 8$ minutes and 23.5 \pm 12 minutes, respectively. These time durations were no different from the ones for all the 5344 colonoscopies performed during this period, with insertion time being 9 \pm 6 minutes, withdrawal time $15 \pm 8$ minutes and total duration $25 \pm 12$ minutes.

Gastrointestinal symptoms were the cause of postcolonoscopy emergency room visits in 22 out of 56 (39\%)

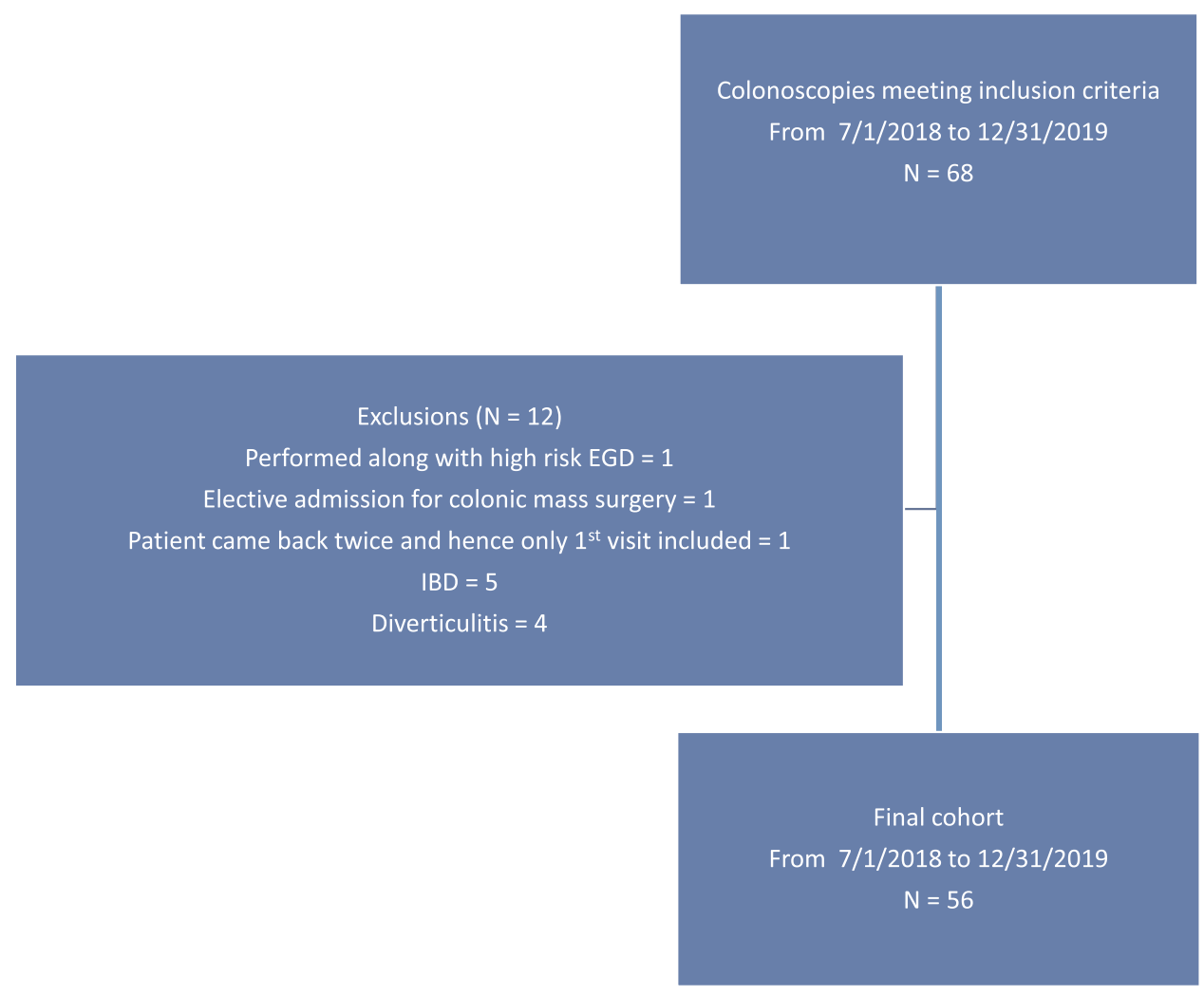

Figure I Flow of patients for the study cohort.

Abbreviations: IBD, inflammatory bowel disease; EGD, esophagogastroduodenoscopy. 
Table I Demographics and Indication for Colonoscopy for Patients Who Presented to the Emergency Department Within 7 Days of Colonoscopy

\begin{tabular}{|l|l|}
\hline Mean age (years) & $\mathbf{5 8} \pm \mathbf{I 2 . 2}$ \\
\hline Gender (n) & \\
Female & 25 \\
Male & 31 \\
\hline Ethnicity ( $)$ & \\
African American & 26 \\
Hispanic & 27 \\
Others & 3 \\
\hline Mean Body Mass Index (kg/m $\left.{ }^{2}\right)$ & $28.7 \pm 6.8$ \\
\hline Mean colonoscopy time (minutes) & $23.5 \pm 12$ \\
\hline Indication for Colonoscopy (n) & \\
Abdominal pain & 1 \\
Abnormal CT scan of the abdomen & 3 \\
Worsening constipation & 1 \\
Chronic diarrhea & 2 \\
Iron deficiency anemia & 8 \\
Perioperative & 1 \\
Rectal bleeding & 8 \\
Screening colonoscopy & 23 \\
Surveillance colonoscopy & 9 \\
\hline
\end{tabular}

Abbreviations: $\mathrm{CT}$, computed tomography; kg, kilograms; m, meter.

patients (Table 2). The leading gastrointestinal cause of an unplanned emergency room visit within 7 days of colonoscopy was abdominal pain, reported by 13 (23\% of study population) patients. The mean time to presentation was 3.4 days (range, 1-6 days), however, when stratified for abdominal pain, it was 2.9 days (range, 2-6 days). The next predominant gastrointestinal complaint was bleeding, observed in nine (16\% of study population) patients (Table 3). Four of these nine patients with gastrointestinal bleeding had polypectomy performed during colonoscopy (overall post polypectomy bleeding rate of $0.07 \%$ ), and three among them required intervention. Two of the four $(50 \%)$ patients with post-polypectomy bleed were taking antiplatelet or anticoagulant medication.

Patients who returned to the emergency room with gastrointestinal symptoms had a significantly higher rate of polypectomy performed during colonoscopy compared with the rest of the patients $(36.4 \%$ vs $11.8 \%, \mathrm{P}=0.04)$ (Table 3). Interestingly, this patient group with gastrointestinal symptoms had a high number of individuals who reported illicit drug use compared with the rest of the patients $(31.9 \%$ vs $5.9 \%, \mathrm{P}=0.02)$. This group also had a larger size polyp, defined as a polyp greater than $1 \mathrm{~cm}$, compared with the rest of the patients $(22.7 \%$ vs $11.8 \%$, $\mathrm{P}=0.29$ ), however, this difference was not statistically significant. When comparing patients who returned with abdominal pain versus all other complaints, the former were found to be younger (mean age 48 years vs 61 years, $\mathrm{P}=0.0013$ ) (Table 4 ) and had a higher percentage of individuals who underwent polypectomy $(36.4 \%$ vs $26.7 \%, \mathrm{P}=0.71)$ or endoscopic mucosal resection $(9 \%$ vs $4.4 \%, \mathrm{P}=0.49$ ). However, other than age, these differences were not statistically significant. In patients with abdominal pain, the use of abdominal pressure to assist in the completion of colonoscopy, was not different from other patients. The mean insertion time ( $8 \pm 4$ minutes), withdrawal time (14 \pm 7 minutes) and total duration of procedure ( $24 \pm 8$ minutes) in patients who presented with abdominal pain were similar to durations noted in our overall colonoscopies performed during this study period.

\section{Discussion}

Colonoscopy is one of the most commonly performed gastrointestinal procedures which is utilized primarily for colorectal cancer screening and surveillance of colon polyps. With the US population of adults older than 50 years of age increasing, the number of annual screening colonoscopies has risen from $34 \%$ in 2000 to $63 \%$ in 2015. ${ }^{6}$ Colonoscopy, although a low-risk procedure, is not without its share of complications. For a long time, no metric to assess the quality and competence of the endoscopist existed. In 2000 gastroenterology societies collaborated to form the US Multi-Society Task Force on Colorectal Cancer and set forth the quality indicators for colonoscopy examination. ${ }^{7}$ These measures were then adopted by the ASGE and American College of Gastroenterology (ACG) taskforce on quality in endoscopy in 2006. ${ }^{8}$ Measures such as adenoma detection rate (ADR) assessed the quality of the endoscopy, whereas measures such as bleeding and perforation rates assessed the safety of the colonoscopy examination. Measures to assess the quality of care provided by the facility where the colonoscopy was performed were still lacking. Hence in 2016, CMS developed one such metric to evaluate the quality of care provided by the facility by assessing the rates of unplanned hospital visits within 7 days after colonoscopy. $^{5}$

The use of such a nonspecific measure to rate the facilities was widely criticized by the experts in the field. It was believed that such a measure would discourage advanced endoscopists from treating complex polyps, 
Table 2 Reason for Post-Colonoscopy Emergency Room Visit

\begin{tabular}{|c|c|c|c|}
\hline Total Events $100 \%(\mathrm{~N}=56)$ & $\begin{array}{l}\text { Related to Colonoscopy or } \\
\text { Anesthesia } \\
32 \%(\mathrm{~N}=18)\end{array}$ & $\begin{array}{l}\text { Probably Related to } \\
\text { Colonoscopy or Anesthesia } \\
27 \%(N=15)\end{array}$ & $\begin{array}{l}\text { Unrelated to Colonoscopy or Anesthesia } \\
41 \%(N=23)\end{array}$ \\
\hline \multirow{2}{*}{$\begin{array}{l}\text { Gastrointestinal complaint } \\
(\mathrm{N}=22)\end{array}$} & Abdominal pain $(n=13)$ & & \\
\hline & $\begin{array}{l}\text { Gastrointestinal bleeding }(n=5) \\
\text { - } 4 \text { = post-polypectomy bleed } \\
\text { I = bleeding after biopsy done } \\
\text { during the concomitant upper } \\
\text { gastrointestinal procedure }\end{array}$ & & $\begin{array}{l}\text { Gastrointestinal bleeding }(\mathrm{n}=4) \\
\text { - } 3 \text { patients had index colonoscopy with hemor- } \\
\text { rhoidal bleeding and returned to the emer- } \\
\text { gency room with the same complaint } \\
\text { - I patient had index colonoscopy for diverticu- } \\
\text { lar bleeding and returned to emergency room } \\
\text { with the same complaint }\end{array}$ \\
\hline Orthopedic complaint $(\mathrm{N}=6)$ & & & $\begin{array}{l}\text { Hand pain }(n=2) \text {, back pain }(n=2) \text {, shoulder pain } \\
(n=1) \text {, toe pain }(n=1)\end{array}$ \\
\hline Pulmonology complaint $(\mathrm{N}=5)$ & & $\begin{array}{l}\text { Cough }(n=1) \text {, asthma }(n=1) \text {, } \\
\text { shortness of breath }(n=1) \text {, } \\
\text { pneumonia }(n=1)\end{array}$ & Viral syndrome $(n=1)$ \\
\hline Urological complaint $(\mathrm{N}=5)$ & & & Urinary tract infection $(n=4)$, hematuria $(n=1)$ \\
\hline Neurology complaint $(\mathrm{N}=5)$ & & $\begin{array}{l}\text { Headache }(n=3) \text {, seizure }(n=1) \text {, } \\
\text { stroke }(n=1)\end{array}$ & \\
\hline Cardiovascular complaint $(\mathrm{N}=5)$ & & $\begin{array}{l}\text { Chest pain }(n=3) \text {, high blood } \\
\text { pressure }(n=1) \text {, bradycardia }(n=1)\end{array}$ & \\
\hline Hematology complaint $(\mathrm{N}=2)$ & & & Anemia $(n=2)$ \\
\hline Dermatology complaint $(\mathrm{N}=\mathrm{I})$ & & & Rash and pruritus $(\mathrm{n}=\mathrm{l})$ \\
\hline Ear, Nose and Throat complaint $(\mathrm{N}=\mathrm{I})$ & & & Earache $(n=1)$ \\
\hline Nephrology complaint $(\mathrm{N}=\mathrm{I})$ & & Oliguria $(n=1)$ & \\
\hline Vascular complaint $(\mathrm{N}=\mathrm{I})$ & & & Arterio-venous fistula bleeding $(n=I)$ \\
\hline Psychiatric complaint $(\mathrm{N}=\mathrm{l})$ & & & Detox from substance abuse $(n=l)$ \\
\hline General surgery $(N=1)$ & & & Needle puncture wound $(n=1)$ \\
\hline
\end{tabular}

leading to an increase in surgical resection of benign polyps and hence defeating the very purpose of screening colonoscopy. Our results show that overall $1.05 \%$ of our study patients had an unplanned emergency room visit after their colonoscopy. Among these patients with unplanned visits, $41 \%$ of the visits were for reasons unrelated to colonoscopy. A detailed review of reasons for such visits highlights the behavior of patients in our community and their preference to utilize the emergency room over ambulatory care clinics. Though $32 \%$ of post-colonoscopy unplanned emergency room visits were directly related to colonoscopy, $27 \%$ resulted from cardiovascular or neurological reasons that were presumably related to the anesthesia administered during the colonoscopy. In such cases, it is also difficult to establish the causality between the symptoms and the procedure.

This study further emphasizes the fact that patient visits within 7 days of colonoscopy are not necessarily related to the colonoscopy and hence do not determine the quality of procedure or care delivered. Out of all patients who returned, about a third presented with symptoms related to colonoscopy and a quarter returned due to reasons probably related to anesthesia, these visits were mostly unavoidable. Interestingly, our study shows a significantly higher number $(31 \%$ of study patients) of illicit drug users presenting with gastrointestinal complaints after a colonoscopy. It is unclear why these drug users presented more often with 
Table 3 Comparison of Patients Who Presented with Gastrointestinal versus Other Complaints

\begin{tabular}{|l|l|l|l|}
\hline Variables & $\begin{array}{l}\text { Gastrointestinal Complaints } \\
\mathbf{N}=\mathbf{2 2}\end{array}$ & $\begin{array}{l}\text { Other Complaints } \\
\mathbf{N}=34\end{array}$ \\
\hline Age (years) & $56.6 \pm 15.2$ & $58.9 \pm 9.9$ & $\mathbf{P}$ value \\
Gender \% (M:F) & $59.1: 40.9$ & $52.9: 47.1$ & 0.4951 \\
Race \% & $59: 32: 9$ & $38: 59: 3$ & 0.7847 \\
Body mass index $\left(\mathrm{kg} / \mathrm{m}^{2}\right)$ & $27.3 \pm 6.8$ & $29.6 \pm 6.8$ & 0.1215 \\
Total colonoscopy time (minutes) & $24 \pm 11.2$ & $23.2 \pm 12.7$ & $1 / 34=2.9 \%$ \\
Abdominal pressure and repositioning used & $1 / 22=4.5 \%$ & $3.1 \pm 2.0$ & 0.2217 \\
Charleston index & $3.3 \pm 2.6$ & $11.8 \%$ & 0.8106 \\
Polypectomy & $36.4 \%$ & $11.8 \%$ & 1.000 \\
Polyp size I cm or more & $22.7 \%$ & $11.8 \%$ & 0.7468 \\
HGA & $13.6 \%$ & $17.6 \%$ & 0.0448 \\
LGA & $18.2 \%$ & $38.2 \%$ & 0.2939 \\
Any biopsy or polypectomy done & $45.5 \%$ & $2.9 \%$ & 1.000 \\
EMR & $9.1 \%$ & $17.6 \%$ & 1.000 \\
Any clinic visits between Colonoscopy to ED visit & $9.1 \%$ & $76.5 \%$ & 0.5548 \\
ED visit within last Imonth & $59.1 \%$ & $3.4 \pm 1.8$ & 0.5548 \\
Time lapse between colonoscopy and ED visit (days) & $3.3 \pm 1.7$ & $17.6 \%$ & 0.4595 \\
Alcohol abuse & $22.7 \%$ & $17.6 \%$ & \\
Psychiatric illness & $36.4 \%$ & $5.9 \%$ & \\
Illicit drug use & $31.9 \%$ & 0.2355 \\
\hline
\end{tabular}

Abbreviations: M, male; F, female; cm, centimeter; HGA, high-grade adenoma; LGA, low-grade adenoma; EMR, endoscopic mucosal resection; ED, emergency department; kg, kilograms; m, meter.

Table 4 Comparison of Patients Who Presented with Abdominal Pain versus Other Complaints

\begin{tabular}{|c|c|c|c|}
\hline Variables & $\begin{array}{l}\text { Abdominal Pain } \\
\mathrm{N}=1 \mathrm{I}\end{array}$ & $\begin{array}{l}\text { Other Complaints } \\
N=45\end{array}$ & $P$ value \\
\hline Age (years) & $47.8 \pm 13.7$ & $60.5 \pm 10.5$ & 0.0013 \\
\hline Gender \% (M:F) & $45: 55$ & $58: 42$ & 0.0893 \\
\hline Race \% & $55: 27: 18$ & $45: 53: 2$ & 0.0595 \\
\hline Body mass index $\left(\mathrm{kg} / \mathrm{m}^{2}\right)$ & $26.5 \pm 8$ & $29.2 \pm 6.4$ & 0.2378 \\
\hline Total colonoscopy time (minutes) & $23.2 \pm 8.7$ & $23.6 \pm 12.8$ & 0.9224 \\
\hline Abdominal pressure and repositioning used & 0 & $2 / 45(4 \%)$ & 0.1212 \\
\hline Charleston index & $2.5 \pm 2.4$ & $3.3 \pm 2.2$ & 0.2927 \\
\hline Polypectomy & $36.4 \%$ & $26.7 \%$ & 0.7108 \\
\hline Polyp size I cm or more & $18.2 \%$ & $15.5 \%$ & 1.000 \\
\hline HGA & $9 \%$ & $13.3 \%$ & 1.000 \\
\hline LGA & $9 \%$ & $20 \%$ & 0.6670 \\
\hline Any biopsy or polypectomy done & $4 / 11=36.4 \%$ & $40 \%$ & 1.000 \\
\hline EMR & $9 \%$ & $4.4 \%$ & $0.488 I$ \\
\hline Any clinic visits between Colonoscopy to ED visit & 0 & $8 / 45=17.8 \%$ & 0.3332 \\
\hline ED visit within last I month & $6 / 11=54.5 \%$ & $33 / 45=73.3 \%$ & 0.2796 \\
\hline Time lapse between colonoscopy and ED visit (days) & $3.9 \pm 1.7$ & $3.2 \pm 1.8$ & 0.2480 \\
\hline Alcohol abuse & $27.3 \%$ & $17.8 \%$ & 0.6727 \\
\hline Psychiatric illness & $27.3 \%$ & $24.4 \%$ & 1.000 \\
\hline Illicit drug use & $27.3 \%$ & $13.3 \%$ & 0.3576 \\
\hline
\end{tabular}

Abbreviations: M, male; F, female; cm, centimeter; HGA, high-grade adenoma; LGA, low-grade adenoma; EMR, endoscopic mucosal resection; ED, emergency department; kg, kilograms; m, meter. 
gastrointestinal complaints. However, this finding further highlights the unavoidable nature of certain patient factors that lead to these unplanned postcolonoscopy visits.

We acknowledge that a significant number of patients return after colonoscopy with adverse events or minor incidents related either to the procedure or anesthesia. It is important to capture these patients and study the patient factors associated with such visits. It is also important not to forget the inherent risk associated with these complex procedures and attributing all these visits, especially unavoidable ones, to colonoscopy and rating the procedure quality based on these is unjustified. If the overall goal is to improve patient care, policymakers should explore other ways to monitor the quality of care delivered by the colonoscopy performing facility and not penalize the gastroenterologists for reasons that are not under their control.

A major strength of our study is the inclusion of all adult patients irrespective of age and insurance status as compared with the data published by CMS. This allows us to study the factors associated with these unplanned visits and allows our findings to be more generalizable. We also conducted a detailed review of all visits to highlight patient factors that are not only unavoidable but also unrelated to the procedure. Our study does have a few limitations. Firstly, it is a retrospective study, which has its inherent limitations. The data for all the patients who may have had a visit to emergency departments of other hospitals after colonoscopy is not available to us and may have accounted for an overall lower than national rate of unplanned visits in our study. The sample size of our study group is small and larger sample size studies are needed to understand factors associated with unplanned post-colonoscopy emergency room visits. Lastly, we do not have data available on the method of insufflation used, air versus carbon dioxide, which might have explained some of the differences.

In conclusion, our study highlights that unplanned visits within 7 days of colonoscopy are not necessarily related to the procedure, and those that are, tend to be due to unavoidable patient factors. Hence the CMS measure may not be an accurate determinant of the quality of the procedure or facility care delivered.

\section{Disclosure}

The authors report no conflicts of interest in this work.

\section{References}

1. Peery AF, Crockett SD, Murphy CC, et al. Burden and cost of gastrointestinal, liver, and pancreatic diseases in the United States: update 2018. Gastroenterology. 2019;156(1):254-72 el1. doi:10.1053/j. gastro.2018.08.063

2. Cotton PB, Eisen GM, Aabakken L, et al. A lexicon for endoscopic adverse events: report of an ASGE workshop. Gastrointest Endosc. 2010;71(3):446-454. doi:10.1016/j.gie.2009.10.027

3. Reumkens A, Rondagh EJ, Bakker CM, Winkens B, Masclee AA, Sanduleanu S. Post-colonoscopy complications: a systematic review, time trends, and meta-analysis of population-based studies. $\mathrm{Am}$ J Gastroenterol. 2016;111(8):1092-1101. doi:10.1038/ajg.2016.234

4. Baudet JS, Diaz-Bethencourt D, Aviles J, Aguirre-Jaime A. Minor adverse events of colonoscopy on ambulatory patients: the impact of moderate sedation. Eur J Gastroenterol Hepatol. 2009;21(6):656-661. doi:10.1097/MEG.0b013e328314b7e3

5. Ranasinghe I, Parzynski CS, Searfoss R, et al. Differences in colonoscopy quality among facilities: development of a post-colonoscopy risk-standardized rate of unplanned hospital visits. Gastroenterology. 2016;150(1):103-113. doi:10.1053/j.gastro.2015.09.009

6. Siegel RL, Miller KD, Goding Sauer A, et al. Colorectal cancer statistics, 2020. CA Cancer J Clin. 2020;70(3):145-164. doi:10.3322/ caac. 21601

7. Rex DK, Bond JH, Winawer S, et al. Quality in the technical performance of colonoscopy and the continuous quality improvement process for colonoscopy: recommendations of the US. Multi-society task force on colorectal cancer. Am $J$ Gastroenterol. 2002;97 (6):1296-1308. doi:10.1111/j.1572-0241.2002.05812.x

8. Rex DK, Petrini JL, Baron TH, et al. Quality indicators for colonoscopy. Am J Gastroenterol. 2006;101(4):873-885. doi:10.1111/ j.1572-0241.2006.00673.x

\section{Publish your work in this journal}

Clinical and Experimental Gastroenterology is an international, peerreviewed, open access, online journal publishing original research, reports, editorials, reviews and commentaries on all aspects of gastroenterology in the clinic and laboratory. This journal is indexed on American Chemical Society's Chemical Abstracts Service (CAS)
The manuscript management system is completely online and includes a very quick and fair peer-review system, which is all easy to use. Visit http://www.dovepress.com/testimonials.php to read real quotes from published authors. 